\title{
MYXOEDEMA AND OPEN HEART SURGERY: ANAESTHESIA AND INTENSIVE CARE UNIT EXPERIENCE
}

\author{
D.C. Finlayson and Joel A. Kaplan
}

\begin{abstract}
Myxoedema has been considered a major anaesthetic risk which could be increased by concurrent heart disease. Thyroid ablation with the production of myxoedema has, in the past, been used to control intractable angina. Eight ablated patients (Group I) and five patients with heart disease and incidental hypothyroidism (Group II) presented for open heart surgery. Management included diazepam-narcotic anaesthesia in generally reduced doses, careful monitoring and the use of digoxin, steroids and I-thyroxin given during or after operation. All patients survived. A number of the anaesthetic considerations and potential problems with myxoedema are discussed.
\end{abstract}

Key Words: CoMplications, myxoedema; SuRgERY, open heart.

THE DELIBERATE induction of myxoedema by thyroid ablation using radioactive iodine has been used for control of intractable angina pectoris. ${ }^{1.6}$ Myxoedema was then, to a varying deptee, reversed by exogenous thyroid suppit mentation depending upon the resultant level of angina and its relief by nitrates. With the advent of propranolol and myocardial revascularization, the use of thyroid ablation has now essentially disappeared as a form of treatment for coronary artery disease (CAD).

Review of the literature suggests that anaesthesia and surgery might be hazardous for the patient with myxoedema, particularly when combined with debilitating cardiac disease. ${ }^{2-4}$ Two recent reports suggest that this might not be true and that anaesthesia and surgery might be quite manageable in such patients. 5,6

The anaesthetist is occasionally asked to manage patients who are hypothyroid secondary either to ablation, partial thyroidectomy, or idiopathic causes. This paper reviews our experience with such a group of patients undergoing cardiac surgery.

\section{Patient Material - Management}

The records of Emory University Hospital contain 200 patients with prior thyroid ablation

D.C. Finlayson, M.D., F.R.C.P.(C), Professor of Anesthesiology; and Joel A. Kaplan, M.D., Professor of Anesthesiology; The Cardiovascular Intensive Care Units and Division of Cardiothoracic Anesthesia, Department of Anesthesiology, Emory University School of Medicine, Atlanta, Georgia.

543 for coronary artery disease (CAD). With the advent of coronary angiography, 52 were considered in need of further study and underwent cardiac catheterization. Four of these patients were found to have no significant $C A D$ and were returned to the euthyroid state. The remaining 48 were found to have moderate to severe CAD. Two of this latter group (Patients $1 \& 2$, Table I) underwent repeat cardiac catheterizations which showed no significant progression of the disease during the two and five years preceding operation. These two and six others of the ablated patients (Patients Nos. 3-8) were judged to be candidates for coronary artery bypass grafting (CABG) for the relief of their angina and make up Group I.

Group II consists of patients with heart disease and incidental hypothyroidism (Patients Nos.

9-13). Three underwent CABG. Two of these patients had had previous thyroidectomies for hyperthyroidism and one had idiopathic hypothroidism. The two remaining patients in Group II underwent aortic valve replacement for aortic stenosis. One had hypothroidism secondary to radioactive iodine therapy for hyperthroidism and the other had idiopathic myxoedema.

Specific coronary artery lesions and left ventricular function as determined at cardiac catheterization are shown in Table I.

The total series included 11 men and two women. Their ages ranged from 53 to 67 , with a mean of 60.6 years (Table I).

In Group I thyroid ablation had been carried out for angina in eight patients between 1965 and

Can. Anaesth. Soc. J., vol. 29, no. 6, November 1982 


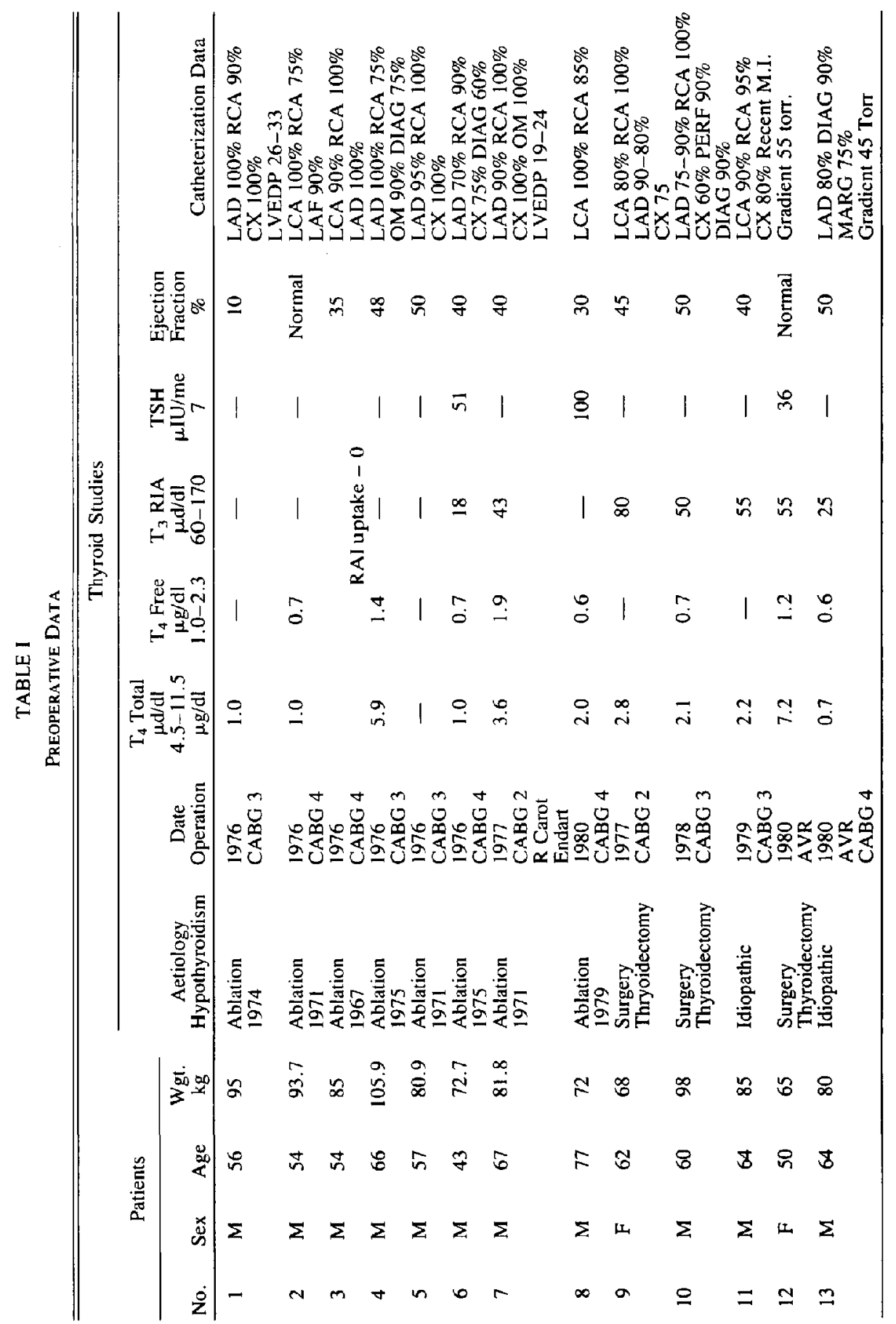


1979 and had been in effect for $2-15$ years. They were also receiving propranolol and nitrates and four had been on modest degrees of thyroid replacement dictated by the severity of their angina until their condition worsened, leading to suspension of its use.

Thyroid supplementation was withheld to assist in the control of angina two weeks or more before operation in all except for patients Nos. 4 and 11 , in whom it was stopped during the week which preceded operation. One of these patients (4) and one other (1) were given L-thyroxin 25 micrograms orally on the day before the operation, as part of the premedication (Table II). All were clinically hypothyroid at the time of operation. There was laboratory confirmation of their hypothyroid status in all but three patients. Patient No. 4 had thyroid function studies done after the preoperative thyroid had been given, patient No. 11 had studies done four days after stopping supplementation, and in patient No. 5 , thyroid studies were unavailable.

Details of anaesthesia are shown in Table II. Premedication consisted of morphine, diazepam and scopolamine in somewhat reduced doses, and thyroxin in two patients on the day before operation. Anaesthesia was induced with diazepam and Innovar or combinations of narcotics and maintained with additional narcotics and diazepam plus nitrous oxide, oxygen, pancuronium or curare. The mean doses of morphine and diazepam were 46 and $19 \mathrm{mg}$ respectively for both groups. Monitoring included electrocardiogram leads II and V5, nasopharygeal temperature, and a radial artery catheter in all patients. In four patients a central venous pressure catheter was used, supplemented in two by a left atrial pressure catheter, to assess filling pressures. A pulmonary artery catheter was used in the remaining nine patients. Serial haemodynamic measurements were made in eight of these during the operation and in the postoperative period.

A bubble oxygenator (Optiflo) with crystalloid prime and cold potassium cardioplegia was used in all patients during cardiopulmonary bypass (CPB). An average of 3.3 coronary grafts were placed (Table I). Methylprednisolone 1 to 2 grams was given before CPB in all but four patients in whom steroids were begun upon arrival in the intensive care unit (ICU), (Table III). Digoxin was continued if in use (four patients) and begun in the remainder either in the operating room or immediately upon reaching the ICU. L-thyroxin was given after revascular- ization, but before the end of CPB in all but five patients, and in the ICU shortly after operation in all but one patient. L-thyroxin was withheld in the operating room in three of these five patients after the development of hypertension, and in the two patients who had undergone aortic valve replacement after the development of ventricular ectopy. In addition, it was further withheld in one of these latter patients (noted below) in the ICU for several days due to persistent ectopy. The dosage used ranged from 25 to 200 micrograms given intravenously on the day of operation. This comprised an average of 37.5 micrograms given in the operating room and 77.1 micrograms in the ICU for a total of 114.6 micrograms.

\section{RESULTS}

Serial haemodynamic measurements were carried out in eight patients before induction of anaesthesia, as well as before and after CPB. (Table II) Mean cardiac index (CI) and systemic vascular resistance (SVR) on arrival in the operating room were $1.901 \cdot \mathrm{min}^{-1} / \mathrm{m}^{2}$ and 1961 dynes. $\mathrm{sec} \cdot \mathrm{cm}^{-5}$ respectively; 1.76 and 2147 before CPB; and 2.24 and 1524 after CPB. All seven patients had cardiac indices greater than $2.31 \cdot \mathrm{min}^{-1} / \mathrm{m}^{2}$ and resistances less than 1500 when normothermic after admission to the ICU.

During anaesthesia and operation a number of problems related to hypothroidism were anticipated. These included increased cardiac and respiratory depression, prolonged effects of drugs, difficulty in weaning from CPB, prolonged hypothermia and major requirements for cardiovascular support postoperatively. In fact, only one patient (No. 1) who had two previous myocardial infarctions and an ejection fraction of 5 to 10 per cent, was difficult to wean from bypass - requiring vasodilator and inotrope infusions, glucose and insulin and the intraaortic balloon pump. Patient No. 7 , in heart failure preoperatively, required an infusion of dopamine for the first 48 hours after operation. Patient No. 12, in whom the institution of thyroid supplementation after aortic valve replacement was delayed several days because of marked ventricular irritability, and in whom steroids had been discontinued, became hypotensive, obtunded, and markedly hyponatraemic by the fifth postoperative day, 48 hours after the institution of thyroid replacement. Three patients required vasodilators briefly for the control of hypertension after operation. (Table III). 


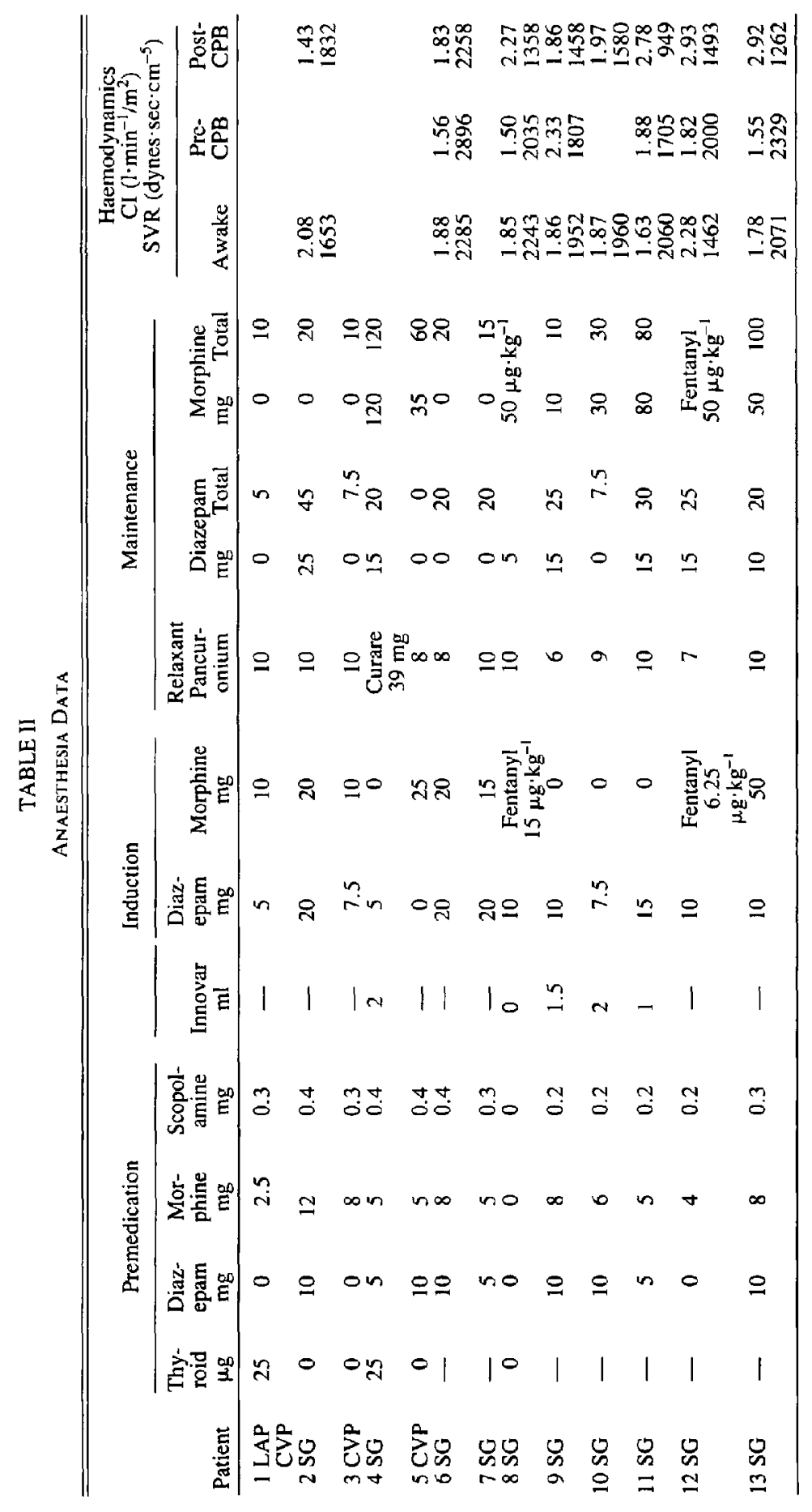




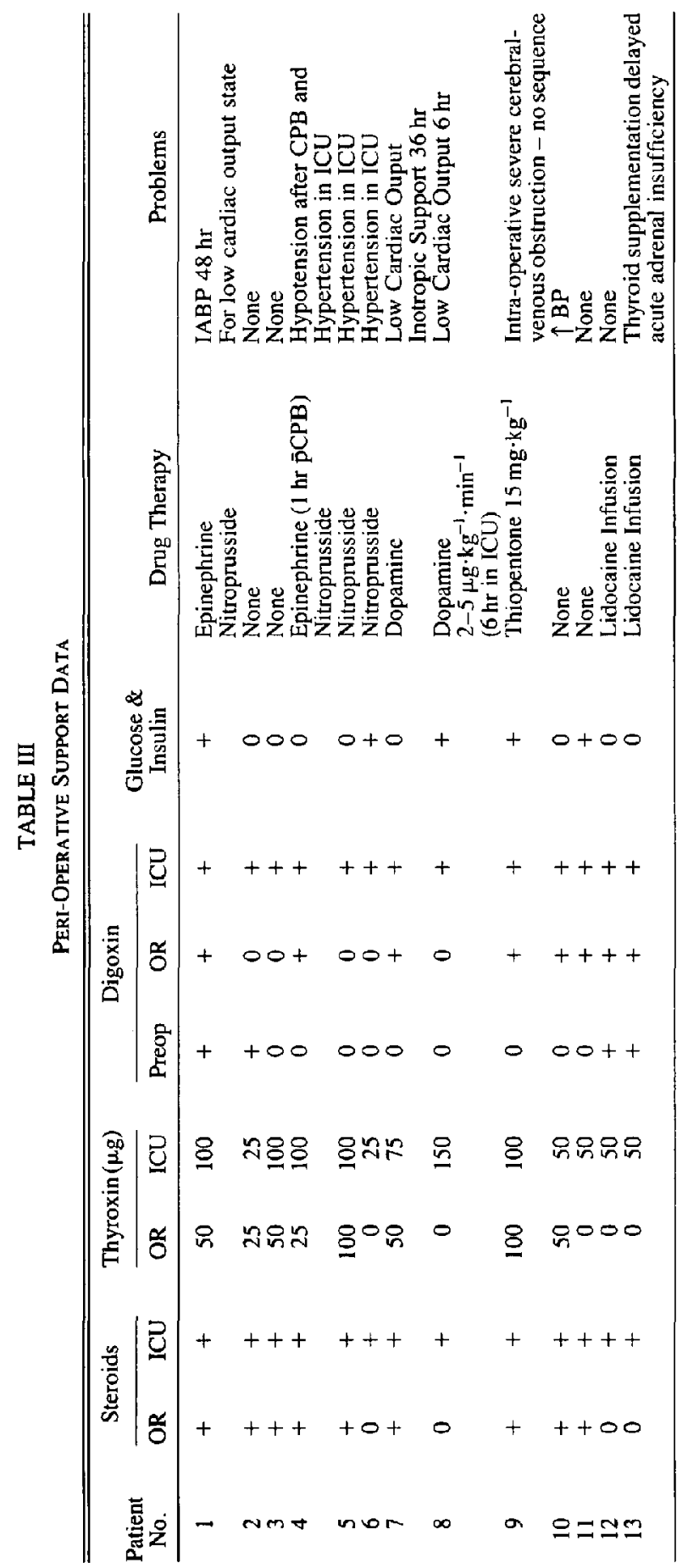


These problems were managed without incident and the subsequent clinical course of the entire group was uneventful. There were no episodes of hypothermia, prolonged respiratory depression, or difficulty weaning from mechanical ventilation. These patients have been followed up for 2-54 months with one late death in patient No. 1, 11 months after operation.

\section{Discussion}

Ablation and deliberate creation of myxoedema to reduce cardiac work and to treat intractable angina was first described by Blumgart in 1948.' In selected patients without congestive failure he was able to produce "good" to "excellent" relief in 76 per cent of cases. Myxoedema leads to hypercholesterolaemia and hyperlipidaemia, but in Blumgart's patients this did not appear to increase the rate of development of atherosclerotic lesions. In two of the patients in Group I who were restudied, progress after several years was also shown to be very slow. Clinically the same appeared to be the case in the remainder of the patients.

The general level of depression of cellular function in severe untreated hypothroidism has been reported to lead to problems with all organ systems during anaesthesia and surgery. Central nervous system disorders such as altered mentation and failure of thermoregulation and respiratory control were not seen in our patients. Similarly, enhancement or prolongation of the effect of the anaesthetic drugs was not apparent. Metabolic disorders such as hypoglycaemia and hyponatraemia were not seen except in the patient in whom, after the late reinstitution of thyroid supplementation, a low serum sodium developed.

Marked bradycardia, arrhythmias, cardiomegaly, pericardial effusions, impaired contractility, congestive heart failure and labile blood pressure all have been reported in hypothyroid patients. ${ }^{2,3}$ Our patients all showed the characteristic electrocardiogram and varying degrees of cardiomegaly; however cardiac rhythm was normal and cardiovascular function was relatively stable. In eight patients ejection fraction was less than 50 per cent and, in one of these, severe congestive heart failure was present and clearly related to previous myocardial infarction. Only two of eight patients studied haemodynamically had cardiac indices greater than $2 \mathrm{l} \cdot \mathrm{min}^{-1} / \mathrm{m}^{2}$, or systemic vascular resistance less than 1500 dynes $\cdot \mathrm{cm} \cdot \mathrm{sec}^{-5}$ on arrival in the operating room.
With careful monitoring and anaesthesia administration, however, it was possible to bring these patients safely off $\mathrm{CPB}$ and through the postoperative period.

The report of six hypothyroid patients by Paine, et al. ${ }^{5}$ noted that two were managed without preoperative thyroid supplementation. In the remaining four, who were supplemented, there were two deaths. There was no observable benefit from preoperative thyroid supplementation in patients No. 1 and 4 of our series. When considered in regard to the potential for producing angina and myocardial infarction due to increased oxygen demand in an ischaemic heart, the risk of thyroid administration did not seem justified. It was therefore withheld in the remainder of our patients, with good results.

Aggressive administration of intravenous $\mathrm{L}$ thyroxin while on CPB appeared clinically to be associated with immediate enhancement of cardiac activity. This did not appear to be counterbalanced by obvious risk. Although immediate onset of activity is not suggested by most of the literature relating to thyroxin, just such a possibility may occur under some circumstances. ${ }^{7}$

The concomitant use of steroids with re-institution of thyroid replacement has been suggested to reduce the risks of an inadequate stress response by the pituitary-adrenal axis. ${ }^{2,8}$ Steroids were used concomittantly in all of these patients except No. 12. Aggressive administration of L-thyroxin to this patient 48 hours after steroids had been discontinued was followed by the development of marked central nervous system and cardiovascular depression and severe hyponatraemia. Although other causes of fluid and electrolyte problems are common in such patients, this may well have represented acute adrenal insufficiency.

Myxoedema is without question a disabling disease which reduces the capacity to respond to stress. Reactivity of the autonomic nervous system and the pituitary-adrenal axis is diminished. Therefore anaesthesia and surgery can be more life-threatening. However the risks cited in the past possibly related more to the lack of monitoring and the inappropriate use of volatile anaesthetic drugs in patients with grossly reduced circulatory reserves and metabolic capacity. It is clear that adequate preparation and careful monitoring avoided major problems in this group of patients.

In summary, we would recommend withholding preoperative thyroid medication in this group of patients. In addition, with good preop- 
erative preparation, aggressive monitoring and moderate premedication, the intravenous anaesthetic drugs can be used safely. Supplementation in the operating room or the intensive care unit with digoxin, steroids, and thyroxin permits relatively normal patient management. Further, good postoperative respiratory function should permit routine extubation.

\section{REFERENCES}

1. Blumgart, H.L., Freedrerg, A.S \& KurLAND, G.S. Treatment of incapacitated euthyroid cardiac patients with radioactive iodine: summary of results in treatment of 1070 patients with angina pectoris or congestive failure, J. Am. Med. Ass. 157: 1 (1955).

2. Aввотt, T.R. Anaesthesia in untreated myxoedema: report of two cases, Br. J. Anaes. 39 . $510(1967)$.

3. Katz, J., Benumof, J. \& Kadis, L.B. Anesthe- sia and uncommon diseases: pathophysiologic and clinical correlations, 2nd Ed. Philadelphia: Saunders (1981). Pender, W.E., Basso, L.V. Chapter 5: Diseases of the endocrine system, pp 178-179.

4. KIM, J.M. \& HaCKMAN, L. Anesthesia for untreated hypothyroidism: report of 3 cases, Anaes. \& Analg. 56: 299 (1977).

5. Paine, T.D., Rogers, W.J., Baxley, W.A. \& RUSSELL, R.O. Coronary arterial surgery in patients with incapacitating angina pectoris and myxedema, Am. J. Cardiol. 40: 226 (1977).

6. Weinberg, A.D., Marsh, H.M., Brennan, M.D., Gorman, C.A. \& O'Fallon, W. Risks of surgery in hypothyroid Patients; Abstract, Crit. Care Med. 9: 250 (1981)

7. STERLING, K. Thyroid hormone action at the cell level (Two Parts) N. Engl. J. Med. 300: (3)117 \& 300: (4) 173 (1979).

8. Martial, J.A., Seeburg, P.H., Guenzi D. GOODMAN, H.M. \& BAXTER, J.D. Regulation of growth hormone gene expression: synergistic effects of thyroid and glucocorticoid hormones, Proc. Nat. Acad. Sci. USA, 74: 4293 (1977).

\section{RÉsumÉ}

La revue de la littérature indique que le myxoedème est considéré comme un facteur de risque anesthésique et chirurgical majeur et que la présence concommittante d'une pathologie cardiaque vient augmenter le risque. Or, la création délibéré de myxoedème (par thyroüdectomie) a été préconisée et effectuée dans le passé comme thérapie des états d'angine instable rebelles.

Huit malades ayant subi une thyroïdectomie à cette fin, ainsi que cinq patients présentant une pathologie cardiaque associée à une hypothyroïdie ont subi une chirurgie cardiaque dans notre institution. La conduite anesthésique de ces cas incluait l'emploi de diazépam avec des analgésiques à doses plus petites qu'à l'accoutumée, un monitoring rigoureux des malades et l'administration per ou post opératoire de digoxine, de corticostéroïdes et de lévothyroxyne. Tous les opérés ont survécu. Certains problèmes associés à la présence d'un myxoedème et les condirérations anesthésiques pertinentes sont discutés. 